\title{
Estimating economic loss from cascading infrastructure failure: a perspective on modelling interdependency
}

\author{
Scott Kelly
}

\begin{abstract}
Infrastructure failure can cause significant disruption of economic activity. The size of economic loss is a direct function of the interdependencies between infrastructure and economic systems raising important questions about infrastructure vulnerability and resilience. Economic theory is important in this regard as it makes a distinction between damage to infrastructure (stock) and how this may transfer to losses in economic productivity (flow). In order to capture the economic consequences of infrastructure failure, various economic models have been proposed to represent the multimodal complex networks and capture the effects of cascading infrastructure failure. There is still no consensus on the correct approach for estimating economic loss. The method commonly known as input-output analysis has gained the most attention in recent years for its ability to model indirect or higher-order economic losses. The typical input-output approach has spawned an entire field of related models which include: the inoperability input-output model (IIM); Ghosh supply-side model; dynamic input-output models; key-linkages analysis; as well as inventory based models amongst others. Amongst the various methods used to model infrastructure failure this paper identifies the assumptions and shortcomings that must be overcome to produce better estimates of economic loss. Firstly, critical infrastructure systems are connected to the economy through both physical and economic linkages. Models need to capture both types of linkage to accurately represent how cascading infrastructure failure will lead to economic loss and then how sectoral losses may have an indirect impact on infrastructure systems. Secondly, input-output based approaches assume that the economic structure within an economy remains stable during a disaster and throughout the recovery process. New models are required that are able to capture substitution of goods and structural change within an economy. Thirdly, models of economic loss are generally deterministic in nature and thus give no indication about the uncertainty behind model-based estimates. Economic loss estimates using probability theory and methods such as Monte-Carlo simulations or fuzzy logic may prove to be important avenues for quantifying uncertainty in economic loss estimates resulting from infrastructure failure.
\end{abstract}

Keywords: Infrastructure; Cascading failure; Input-output; Economic loss

\section{Background}

Infrastructure networks such as energy, transport, telecommunications, water and waste water systems are complex interconnected systems. Failure in any one of these systems or across multiple systems may cause cascading failure across multiple infrastructures and have a significant impact on productivity and economic output.

Correspondence: sjk64@cam.ac.uk

Department of Land Economy, 19 Silver Street, Cambridge CB39EP, United Kingdom
This paper will first introduce a general theoretical framework for thinking about the dynamic process of economic loss and recovery. It will highlight the important distinction that must be made between damage to physical infrastructure (stock) and how this relates to loss in economic output (flow). Within the literature there are four distinct methods that have been successfully implemented to estimate economic loss resulting from infrastructure failure. These are: (1) statistical/ econometric methods, (2) computer general equilibrium models (CGE); (3) input-output analysis; and, (4) cost-

\section{Springer}


benefit analysis. Input-output models have gained significant traction over the last decade because of their ability to describe intersectoral interdependencies and estimate the cost of cascading failure. A review of the literature has shown that there are no models that simultaneously calculate physical interdependencies between critical infrastructure sectors; physical interdependencies between infrastructure and non-infrastructure; and, economic interdependencies across both infrastructure and non-infrastructure sectors.

\section{Motivation}

Over the last decade there has been growing interest in the estimation of economic impacts caused by infrastructure failure. Given the expanding interest in this area and the growing number of new methods being proposed, questions are rightfully being asked about the validity and inter-comparability of different models and methods that are being used. The contribution of this paper is to critique these existing methods and make suggestions for how these methods might be improved and their weaknesses ameliorated. Although it is acknowledged that different types of disasters will have varying impacts across different infrastructure sectors, the paper only discusses failure in the context of disasters in general terms. It does not prescribe the type of disaster causing infrastructure to fail, and assumes there is a period of time in which infrastructure will be nonoperational and therefore lead to economic consequences. No method is found to offer a comprehensive solution for estimating the economic loss from infrastructure failure, but some methods are found to work better in some situations depending on the type of question(s) being asked. The aim and novelty of this paper is therefore to provide an overview of the strengths and weaknesses of the different approaches to estimating the economic impacts of infrastructure failure with suggestions for how these may be improved. Given the popularity of using Input-output (I-O) methods, a large section of this paper is devoted to addressing the main criticisms and shortcomings that arise when using I-O methods for estimating the economic impacts of infrastructure failure.

\section{Structure of paper}

The paper is organised as follows. The section titled "Early development of economic loss models" provides a description on the early development of economic loss models and how research methods have evolved over the last four decades. The section titled "The estimation of economic loss" will give some practical examples for estimating economic loss and the different approaches that can be used to compare counterfactual scenarios. The section titled
"Infrastructure and the economy as a complex interconnected system" will introduce critical infrastructure as a complex interconnected system and why special models are required to estimate the impacts of infrastructure failure. The section titled "Empirical approaches to modelling economic loss" will compare and contrast the four most widely used methods for estimating economic loss from infrastructure failure. The section titled "Strengths and weaknesses of different Input-Output Models" introduces and then discusses the strengths and weaknesses of several I-O based methods and the section titled "How to improve economic loss estimation from infrastructure failure" provides some recommendations for how modelling economic loss from infrastructure needs to be improved to overcome these limitations.

\section{Early development of economic loss models}

It was not until 1970s onwards that a debate on the definition of what constitutes a disaster started to materialize (Rodriguez et al. 2007). Many researchers have put forward various ideas for what constitutes a disaster with some agreement on underlying themes (Fritz and Marks 1954; Perry et al. 1981; Perry et al. 1981; Quarantelli 2005). From social theory there is consensus that a disaster implies deviations from routine social order (Cisen and Clark 1962; Stallings 1998), involves irreversible loss and a period of recovery (Buckle 2005) and that overall impacts resulting from the disaster are directly under human or societal control (Mileti 1999). Smith (2005) successfully argued that disasters are events that implicitly cause death, damage and considerable social, political and economic disruption. More recently it has been recognised that disasters can be categorised into two types: slow-onset and fast-onset (Yu et al. 2014). Taken in this regard disasters therefore either involve a sudden collapse and cause considerable harm and interruption to normal procedures, or gradually worsen over time. For the interest of this paper we are primarily concerned with discussing the effects of sudden infrastructure failure. While several authors have attempted to define disasters in an economic context, it was not until the pioneering work by Dacy and Kunreuther (1969) and Cochrane et al. (1974) that the first framework for analysing the full scope of economic impacts caused by disasters was put forward using I-O analysis. More recently, the economic theory behind various disaster impact methodologies was reviewed and consolidated by Okuyama (2004a), Hallegatte and Przyluski (2010) and Cavallo and Noy (2010). Within the literature concerned with estimating the economic impact of disasters, there are those that consider the effect on economic output usually over the short-run (i.e., GDP) and those that examine the effects on economic growth usually over the long-run (i.e., GDP growth rates). 


\section{The estimation of economic loss}

Economic loss is the difference in economic output between a baseline BAU (Business As Usual) scenario and economic output in the disaster scenario. Economic output in the disaster scenario models the projected economic output as a consequence of the disaster. The counterfactual is the BAU scenario and is typically measured as the expected economic output assuming no disaster has occurred. Economic output is usually defined as the productivity in an economy (usually) over one year. Estimating economic loss therefore requires integrating lost output over time. In economic loss modelling, there is not an agreed time-span over which losses should be estimated. Typically, the first time-point is taken as the time the disaster occurs, and the second time-point varies depending on what the loss estimate is trying to capture. Several options include: (1) one year after the disaster; (2) within the same financial year; (3) the time it takes for economic output to match predisaster output; (4) the time it takes for output to reach output if the economy had continued to grow; (5) losses recorded in perpetuity and discounted to a baseline year; (6) an annual multiple from the time the disaster occurred (e.g., 1,2,5, 10 years).

Whatever method is chosen economic loss is the integrated difference of economic output under the counterfactual trajectory (when no disaster occurs) minus the integrated economic output in the disaster scenario. Estimating economic loss requires not only careful analysis of the size of the initial impact, but also the recovery period which must take into account the changing rate of growth of the economy after the disaster and under counterfactual scenario. The rate of growth after the disaster will determine the length of time it takes for the economy to return to an equilibrium or 'new normal' growth rate. The process of understanding the impacts resulting from a disaster therefore involve a sequential analysis of the events precipitated by the initial shock and ending with a 'new normal' economic state (Buckle 2005). Such an analysis typically starts with understanding the magnitude and probability of various hazards, the exposure and vulnerability of physical, social and political systems and the resilience of the economy as it recovers and reaches a new growth trajectory. This is important for understanding economic loss calculations, as it is both the initial drop in economic output and the resulting period of recovery over which the economy is operating below its projected baseline growth that is required to capture the full estimate of economic loss.

\section{Infrastructure and the economy as a complex interconnected system}

Critical infrastructures are highly interconnected and mutually interdependent in complex ways. Identifying, understanding and analysing infrastructure interdependencies represent a significant challenge with important ramifications for disaster related research. The challenges are further exacerbated by the breadth and complexity of critical national infrastructure. Critical infrastructures affect all areas of daily life and include electric power; natural gas; petroleum production and distribution; telecommunication networks, water supply systems, waste and sanitary systems; as well as rail, road and shipping networks. These systems are fundamental to national security, economic prosperity and social well-being. Moreover, infrastructure is a unique form of capital in the way it contributes to economic activity and output. Economic loss models therefore need to take into account the complex relationship between different critical infrastructure systems as well as the complex relationship between infrastructure and the economy.

Critical infrastructure systems are often considered as complex adaptive systems (Brown et al. 2004). Each infrastructure as identified above, consists of a collection of components in an intricate web that when taken as a whole can be considered as 'complex infrastructure' or infrastructure belonging to a 'system of systems'. For example, the electricity system consists of power generating plants, transformers, capacitors and transmission lines etc. that connect the various components of the power grid together. In the same way that components within each infrastructure system interact, there are also interactions that occur between infrastructure sectors (Rinaldi et al. 2001). For example, there is reciprocity in the way the electricity system interacts with the railway network. Electricity provides the energy required for trains to operate, and trains deliver the fuel (coal) required for power stations. Not only is there interaction between infrastructure systems but there is also interaction between infrastructure systems and the economy. In order to fully appreciate the impact of infrastructure failure within an economy, it is necessary to consider the economy as another layer of complexity overlaying the physical infrastructure networks. Thus the inter-linkages between infrastructure and the economy represent additional interdependencies that may have further negative or positive feedbacks on infrastructure systems that may then feed back on the economy. The degree to which infrastructure systems are coupled or linked influences the operational capability of the infrastructure. Links that are loose and flexible offer some resilience to the propagation of shocks. On the other hand, rigid or tight connections leave little flexibility for the system to respond to sudden changes (Rinaldi et al. 2001). Inflexible interdependencies can exacerbate problems where impacts may cascade from one infrastructure to the next. Such mutually interconnected networks represent the possibility for failure in one system to propagate across multiple systems. Understanding and 
modelling such interactions requires the construction of complex network models that are able to capture the deep and often hidden interdependencies between different systems.

However, it is not just cascading failure between different infrastructure systems that is important. Critical infrastructure systems provide the means for production, distribution and consumption within an economy. Economic activity is therefore reliant on operational and well-functioning infrastructure. In a disaster, a direct impact on critical infrastructure will have cascading impacts across different economic sectors. The overall impact on the economy, the recovery and therefore the economic loss from such a failure depends on a multitude of factors including the vulnerability and resilience of the system to different types of disaster. The impact of a shock and how it propagates through an economy depends on the sectors most impacted, the underlying structure of the economy, by the initial shock, and the backward and forward linkages in the economy as the shock propagates. Models that are capable of representing the physical inter-dependencies between infrastructure and the economy are therefore needed to model how shocks may propagate. Only through more accurate modelling of cascade effects is it possible to understand the magnitude of full impacts on the economy and estimate indirect losses. In addition to estimating the overall impact that failed infrastructure may have on an economy, it is also necessary to model the recovery process in the days, weeks and months after the initial impact occurs. This not only requires an understanding of the time and effort required to repair damaged infrastructure, but also how an economy will respond and recover as infrastructure is being repaired. If an economy has spare capacity with stocks of spare inventory, redundancy systems in place, and an ability to switch or transfer production processes and systems, the overall economic impact of the disaster and the recovery process will be faster and the overall economic impact will be less.

\section{Methods}

\section{Empirical approaches to modelling economic loss}

There are two existing methodological approaches to investigate the macroeconomic impact resulting from natural disasters: narrative case studies and quantitative modelling. Quantitative modelling can be further broken down into several more categories. Given the strength and weaknesses of the two different approaches they should be considered as complementary rather than independent alternative methods (Benson and Clay 2004). The remainder of this paper will focus on the strengths and weaknesses of different quantitative approaches. A review of the literature highlights several differences in the main approaches used to tackle the problem of estimating the economic losses resulting from disasters. Expanding on Van der Veen et al. (2003) these approaches can be broadly categorised into the following four approaches:

1. Cost Benefit Analysis (CBA)

2. Computer General Equilibrium (CGE) methods

3. Econometrics

4. Input-output methods

\section{Cost-benefit analysis}

Cost Benefit Analysis (CBA) is typically used by welfare economists with an attempt to incorporate the monetary and non-monetary aspects of disasters into decisionmaking. Most estimations based on CBA estimate changes in utility resulting from changes in consumer surplus and operates on the principle that consumers face costs due to changes in the availability of certain market products, changes in environmental quality, and changes in the availability of products and labour. Many of the disadvantages of using CBA are not unique to this approach, but are still worth noting. For example, CBA requires:

1. accurate estimation and quantification of all costs and benefits;

2. reduction of costs and benefits into monetary terms;

3. increased subjectivity for intangible costs and benefits;

4. controversial estimations of present value and discounting.

\section{Computer general equilibrium models}

Computer General Equilibrium (CGE) models provide a more complete view of the economy taking into account market prices and the effects of exogenous intervention following a disaster and how the economy may respond to changes in supply and demand (Tsuchiya et al. 2007). CGE methods represent an optimised view of consumers and firms in the economy and are primarily concerned with the intervention of governments and other market players, and therefore focus on monetary and fiscal effects such as inflation, unemployment, interest rates and government deficits. Some commentators argue that CGE methods under estimate the true costs of a disaster because they allow short-term input substitution and changes in price which some argue are not fully observed in the disaster aftermath (Hallegatte 2013).

\section{Econometric methods}

Econometrics or long-run methods use valuable information about the economy and historical data on previous disasters to try and predict future impacts (AlbalaBertrand 2013). Econometric analyses are typically 
concerned with estimating the effects of disasters on economic growth rather than overall economic output (Guimaraes et al. 1993; Von Peter et al. 2012; Cavallo et al. 2013) and thus the conclusions reached using these methods must be put in context. Many econometric studies show that the period of recovery after a disaster may either constrain or increase the rate of growth of the economy. In general, it makes sense for an economy to grow faster as it recovers rebounding from the effects of the disaster and catching up to previous output levels. This does not contradict other approaches that instead focus on overall economic output. A weakness of predicting economic growth after a disaster is that it requires significant data on the effects of previous disasters on growth rates both before and after disaster has occurred.

\section{Input-output methods}

Input-output methods have gained the most traction over the last decade for modelling the intersectoral nature and thus cascading effects of disasters. There are several reasons why I-O analysis has become a popular tool for estimating economic loss from disasters and disruption. Firstly, I-O analysis provides detailed sector level information providing comprehensive detail on intersectoral trading relationships between sectors of the economy. In addition, I-O tables are able to show the flow of trade between different sectors to satisfy household consumption, government consumption, exports, and gross fixed capital formation (GCFC). Because data included within I-O tables provides a comprehensive snap-shot of economic activity over the period of one year, and the relationships between different sectors of the economy, it is possible to model how a shock may propagate and thus cause cascading losses through the economy. Thus a major benefit of the input-output approach is in its ability to capture indirect or higher-order effects that are impossible or non-trivial to capture using other methods.

Table 1 lists the main advantages and disadvantages for each of these different methods. Given the recent expansion of I-O based models in the literature, the remainder of this chapter will review several I-O approaches for modelling economic loss from disasters.

\section{Strengths and weaknesses of different input-output models \\ The standard input-output model}

The application of I-O analysis to the study of disasters including both man-made and natural disasters date back to bombing studies completed during the Second World War (Rose 2004). Since this time I-O analysis has been widely applied in the literature to estimate the economic impacts resulting from disasters, mainly because of its ability to reflect the complex structure of the regional economy (Cochrane et al. 1974; Ellson et al. 1984; Romanoff and Levine 1986; Levine and Romanoff 1989; Rose et al. 1997; Gordon et al. 1998; Okuyama 2004b; Santos and Haimes 2004). Because I-O analysis uses a system of linear equations it lends itself to rapid computation and analysis. A key strength of I-O analysis is its ability to estimate higher-order (indirect) effects of a disaster on the whole economy (Rose 2004). It is therefore recognised as a robust analytical tool for conducting interdependency analysis and assessing and managing risk in a system of interconnected infrastructures or industry sectors (Santos and Haimes 2004). Applying I-O analysis thus offers a framework for describing how disaster induced perturbations can propagate due to interconnectedness within an economy.

The basic Input-output model adopts the traditional Leontief framework as described by Equation (1). The vector $\mathbf{x}$ gives the total economic output for each sector of the economy. The matrix $\mathbf{A}$ is a symmetric matrix of technical coefficients and gives the proportional input required to satisfy each unit of output. The vector $\mathbf{f}$ represents the final demand going to households, exports, government expenditure and gross fixed capital formation. Each row - i - of the A matrix represents the jth sectors input requirements from each other sector in the economy. Each column - j - of the A matrix represents the ith sectors output to each other sector of the economy. The relationship between $\mathbf{A}, \mathbf{x}$ and $\mathbf{f}$, thus gives a balanced representation of the economy where all inputs going into the system must equal all outputs generated by the system. The matrix $\mathbf{L}$ represents the Leontief inverse of all input and output requirements to satisfy one unit of final demand, $\mathbf{f}$, and allows for the calculation of the system wide impacts for each unit change in final demand (Miller and Blair 2009).

$$
\mathbf{x}=\mathbf{A} \mathbf{x}+\mathbf{f}=(\mathbf{I}-\mathbf{A})^{-\mathbf{1}} \mathbf{f}=\mathbf{L f}
$$

There are several criticisms that arise from using input-output models for understanding disasters. First, inter-sectoral and inter-regional trade is typically defined using fixed coefficients making the model inflexible to substitution across different industrial sectors and imports. If a disaster results in a drop in demand from one or more sectors, then all other sectors must decrease their output proportionately to match the new demand requirements rather than substitute products from other sectors of the economy. Because of this, input-output models will tend to exaggerate losses and attenuate the recovery process. Second, the model is static in nature and therefore represents a fixed equilibrium structure at a specific point in time. Third, and as an outcome of the 
Table 1 Advantages and disadvantages of various disaster impact methods

\begin{tabular}{|c|c|c|c|}
\hline I-O methods & CGE Methods & Econometrics & Cost-benefit analysis \\
\hline \multicolumn{4}{|l|}{ Advantages } \\
\hline Simplicity & $\begin{array}{l}\text { Can address market based } \\
\text { mechanisms and behaviours }\end{array}$ & Very good forecasting capability & Simplicity \\
\hline $\begin{array}{l}\text { Clear distinction between indirect } \\
\text { and direct effects }\end{array}$ & $\begin{array}{l}\text { Can model broad range of impacts } \\
\text { (e.g., response to price changes) }\end{array}$ & $\begin{array}{l}\text { Rigorous well-developed model } \\
\text { validation }\end{array}$ & $\begin{array}{l}\text { Attempts to capture all } \\
\text { costs and benefits }\end{array}$ \\
\hline $\begin{array}{l}\text { Well suited to distributional } \\
\text { impact analysis }\end{array}$ & Can look at distributional impact & $\begin{array}{l}\text { No major biases in estimating } \\
\text { impacts }\end{array}$ & $\begin{array}{l}\text { Applies expert knowledge } \\
\text { and experience to generate } \\
\text { cost estimates }\end{array}$ \\
\hline $\begin{array}{l}\text { Excellent organisational framework } \\
\text { for data collection and display }\end{array}$ & $\begin{array}{l}\text { Better suited to long term } \\
\text { recovery analysis }\end{array}$ & Incorporates uncertainty & Model transparency \\
\hline $\begin{array}{l}\text { Provides transparent view of } \\
\text { the economy }\end{array}$ & $\begin{array}{l}\text { Can model impacts across a range } \\
\text { of macroeconomic variables. }\end{array}$ & $\begin{array}{l}\text { Does not assume market } \\
\text { equilibrium }\end{array}$ & $\begin{array}{l}\text { Single unit-measurement so } \\
\text { costs and benefits can be } \\
\text { easily compared }\end{array}$ \\
\hline $\begin{array}{l}\text { Well-suited to short-term } \\
\text { recovery periods }\end{array}$ & & & $\begin{array}{l}\text { Benefits are easy to double } \\
\text { count }\end{array}$ \\
\hline \multicolumn{4}{|l|}{$\begin{array}{l}\text { Ability to integrate with other } \\
\text { models (e.g., engineering, econometric) }\end{array}$} \\
\hline \multicolumn{4}{|l|}{ Disadvantages } \\
\hline Rigidity due to linearity & $\begin{array}{l}\text { Intended for long-run equilibrium } \\
\text { analysis }\end{array}$ & $\begin{array}{l}\text { Significant data demand } \\
\text { requirements }\end{array}$ & $\begin{array}{l}\text { Does not account for } \\
\text { economic multiplier } \\
\text { effects }\end{array}$ \\
\hline $\begin{array}{l}\text { Ignores agent behavioural } \\
\text { response to disaster }\end{array}$ & $\begin{array}{l}\text { Usually provides over optimistic } \\
\text { results because of flexibility } \\
\text { of response }\end{array}$ & $\begin{array}{l}\text { Not well suited to modelling } \\
\text { rare events }\end{array}$ & $\begin{array}{l}\text { Subjective costs and } \\
\text { complications }\end{array}$ \\
\hline $\begin{array}{l}\text { Inadequately deals with } \\
\text { monetary interventions }\end{array}$ & $\begin{array}{l}\text { No explicit distinction between } \\
\text { direct and indirect effects }\end{array}$ & $\begin{array}{l}\text { Difficult to obtain disaggregated, } \\
\text { regional data }\end{array}$ & $\begin{array}{l}\text { Single unit-measurement } \\
\text { assumes all things can } \\
\text { be compared }\end{array}$ \\
\hline $\begin{array}{l}\text { Relies on market equilibrium, } \\
\text { while disasters represent a } \\
\text { disequilibrium }\end{array}$ & Assumes all agents optimise & $\begin{array}{l}\text { No explicit distinction between } \\
\text { direct and indirect effects }\end{array}$ & \\
\hline \multirow[t]{3}{*}{$\begin{array}{l}\text { Characterised as providing } \\
\text { over pessimistic results }\end{array}$} & $\begin{array}{l}\text { Assumes agents have perfect } \\
\text { information }\end{array}$ & $\begin{array}{l}\text { Model is based on historical } \\
\text { experience which is unlikely } \\
\text { to provide good }\end{array}$ & \\
\hline & & $\begin{array}{l}\text { Inadequately allows for } \\
\text { economic multiplier effects }\end{array}$ & \\
\hline & & $\begin{array}{l}\text { Research question must be } \\
\text { well specified }\end{array}$ & \\
\hline
\end{tabular}

Table has been modified and expanded from Okuyama (2008)

first two points the market in an I-O framework has an equilibrium orientation and always clears no matter what disturbances have occurred (i.e., total demand equals total supply) (Okuyama et al. 2004). Fourth, I-O models have an explicit lack of resource constraints and there is no implicit allowance for the system to respond to price changes. Finally, impacts are typically applied on the demand side of the economy, with impacts cascading through backward linkages in the economy. This is somewhat incompatible when modelling the impacts of infrastructure, which typically occur on the supply side of the economy. Many authors have attempted to improve these limitations with varying levels of success (MacKenzie et al. 2012; Hallegatte 2013;
Kotzanikolaou et al. 2013; Resurreccion and Santos 2013; Rose and Wei 2013). Suggested solutions to some of these problems will be provided in the discussion section below.

Several more complications arise when trying to apply I-O analysis to infrastructure failure. Infrastructure assets represent a stock of fixed capital, while I-O tables represent monetary flows occurring over a pre-specified period of time. Damage to infrastructure represents a reduction in the 'physical capital stock'. This is different to a reduction in the flow of financial activity. Models attempting to estimate the impact of infrastructure failure are therefore assuming a proportional one-to-one relationship between infrastructure capital and economic output, which may not be correct. In order to estimate 
the economic effects of infrastructure failure it is therefore necessary to map how damaged capital infrastructure translates into a decrease in the availability of infrastructure services, and then how this is captured as lost revenue. Conversion between damage to capital and losses in economic output must first be made before any I-O calculations are even possible. A crude approximation is usually achieved using capital output ratios where the value of capital is divided by the value-added for each economic sector (Okuyama 2009). This is a crude approximation, as economic output losses will most likely vary non-linearly with damage due to the effect of back-up or redundant systems coming online, substitution effects and inventories being drawn down. Such processes are notoriously difficult to model. The size of the disaster also matters, as indirect revenue losses do not scale linearly with the size of the disaster.

For example, a large enough failure within the electricity network may cause the entire system to collapse in a non-linear catastrophic manner. If, hypothetically speaking, twenty per cent of overall expenditure within the manufacturing sector is spent on the consumption of electricity and the electricity network failed, the result from the I-O analysis would indicate a proportional drop in output from the manufacturing sector. In reality however, if the electricity network failed then the manufacturing sector would also fail because production from manufacturing depends almost completely on electricity, and with no electricity, goods cannot be produced. Electricity is thus a critical input into the manufacturing sector. The relationship between infrastructure service provision (i.e., the flow of electricity) and other economic sectors cannot be simply explained by the value of financial transactions occurring between electricity and other economic sectors. Such non-linear critical relationships between infrastructure and the economy are relationships that are therefore not fully captured using standard I-O analysis.

\section{The supply side input-output Ghosh model}

The supply-side Ghosh model represents the inverse interpretation of the demand-side I-O model. Instead of shocks being applied on the demand side of the economy, shocks are applied to the supply-side or primary inputs. This requires interpreting the results of the model somewhat differently. Since the supply driven variation of the classical I-O model was first proposed by Ghosh (1958) many authors have tried to authenticate or debunk it as a legitimate tool for conducting economic analysis (Deman 1988; Rose and Allison 1989; Dietzenbacher and Hoen 2006). Questions on the plausibility of the Ghosh model were first proposed by Oosterhaven (1988) who concluded the supply-driven model was "theoretically implausible" and deterred its use for studying markets that were typically not facing supply constraints. Although the most fervent opposition to the Ghosh model came from Oosterhaven (1988; 1989; 2012) many authors continue to utilise and advocate the use of the Ghosh model for different specialist purposes (Dietzenbacher 1997; Dietzenbacher and Hoen 2006; De Mesnard 2007; De Mesnard 2009; Guerra and Sancho 2011). As already noted, the Ghosh model has proven particularly useful for estimating the impacts of supplyconstrained economies, centrally planned economies or economies with monopolistic behaviour. Several authors have suggested different applications of the Ghosh model for overcoming some of the limitations of the demand driven Leontief model, i.e., the absence of substitution between inputs, constant returns to scale, the absence of capacity constraints and price elasticity's of zero. The Ghosh model may therefore be a more appropriate tool for modelling the effects of infrastructure failure where the effect is to constrain supply within an economy.

Equation (2) shows the basic form of the Ghosh supply driven model. It is equivalent to the demand led Leontief model but differs in one important respect, instead of inputs linearly adjusting to meet final demand, outputs adjust. In the supply driven model elements of the $\mathbf{B}$ matrix have the reverse definition of the A matrix. Coefficients of the $\mathbf{B}$ matrix are interpreted as allocation coefficients and represent the output from each sector as a proportion of total output from the sector as a whole. Thus system wide impacts on the economy can be estimated based on changes to the primary input requirements, $\mathbf{v}$.

$$
\mathbf{x}^{\prime}=\hat{\mathbf{x}} \mathbf{B}+\mathbf{v}^{\prime}=\mathbf{v}^{\prime}(\mathbf{I}-\mathbf{B})^{-1}=\mathbf{v}^{\prime} \mathbf{G}
$$

In the Ghosh supply-driven model, gross production is related to the primary inputs across different sectors and assumes that demand will match supply i.e., demand is perfectly elastic (Oosterhaven 1988). Primary supply is therefore the exogenous driving force within the economy which determines not only total inputs across all sectors of the economy, but also intermediate outputs and final demand. For final demand this means that local production or investment reacts perfectly to any change in supply. The basic assumption in the supply model is that the output distributions are stable in an economic system. Instead of fixed input coefficients, like in the demand side model, fixed output coefficients are assumed in the supply side model. This means that if the output of the $\mathrm{i}$-th sector is halved, then sales from i-th sector to each of the other sectors that purchase from i will also be halved. Given the criticisms surrounding the economic interpretation of the Ghosh model in terms of quantities, Dietzenbacher (1997) reinterpreted the Ghosh model as a price-model. That is, changes in sectoral outputs change due to shifts in the 
equilibrium price, which are caused by price changes of primary inputs. Thus by changing the interpretation of the model to a price-model allows it to be used to estimate the economic effects of infrastructure failure.

\section{Inoperability Input Output Model (IIM)}

The demand reduction inoperability input output model (IIM) was first proposed by Haimes and Jiang (2001) as a method to explore the inoperability of complex interconnected infrastructure systems. The model was later refined and simplified by Santos and Haimes et al. (2002; 2005a; 2005b) who reverted the inoperability model back to using the traditional technical coefficient matrix based on economic transactions alone. The IIM adopts the same principles as the standard I-O model but uses a perturbation vector instead of absolute changes in final demand. The perturbation vector gives values of inoperability between 0 and 1 for directly affected infrastructure sectors. The level of inoperability is usually defined as unrealized production (intended degradation of actual production) divided by the full amount of intended production. According to Santos and Haimes (2004) the term 'inoperability' denotes the level of a systems dysfunction expressed as a percentage of its 'as-planned' production capacity. Therefore, the level of inoperability caused by a disaster can set off a chain of cascading events on interconnected systems.

The IIM is based on the original Leontief structure and therefore retains many of its strengths and weaknesses. It is linear in its transformations to final demand and is therefore deterministic. In the short run and under transient conditions the equilibrium assumption may not always hold. For example, after a widespread disaster, large perturbations may induce non-equilibrium conditions that may dominate. In the long-run this may have the effect of changing the underlying structure of the economy and therefore the coefficients within the technical coefficient A matrix. Predicting the long-term structural changes on an economy caused by a largescale disaster is a complicated process and often requires sophisticated economic models to resolve. In some situations the assumption of linear or constant returns to scale is a valid approximation, but after a disaster some sectors may experience diminishing or increasing returns to scale as demand and total output shift across the economy. Anderson et al. (2007) makes the observation that sectors suffering the highest inoperability are not always the sectors with the largest financial losses due to disruptive economic events. Risk mitigation strategies must therefore address both the magnitude of monetary loss and the relative size of impact upon a particular sector.

The basic form of the IIM is shown in Equation (3). This is an extension of the basic demand side model but instead of returning total losses in absolute economic terms, it returns the percentage of degradation. The vector $\mathbf{q}$ represents the degraded output as a proportion of original output for each sector, the matrix $\mathbf{A}^{\prime \prime}$ is the $\mathbf{B}$ matrix that was presented earlier in the Ghosh model, and $\mathbf{c}$ is the degraded final demand divided by original final demand.

$$
\mathbf{q}=\mathbf{A}^{*} \mathbf{q}+\mathbf{c}^{*}=\left(\mathbf{I}-\mathbf{A}^{*}\right)^{-1} \mathbf{c}^{*}
$$

Despite some of its shortcomings, the IIM it is now one of the most widely used methods for modelling the impacts of cascading infrastructure failure on the economy. This is due to its simple application and seemingly straightforward interpretations of its output. There are now over 65 peer reviewed journal articles that use the IIM to model the propagation of infrastructure failure. Although it is often cited as being a 'physical' inoperability model, this is not correct. The model inputs are still based on financial transactions and the degraded output vector simply represents a reduction in economic value from demand-based inoperability.

\section{Dynamic input output models}

In order to estimate the economic impacts from infrastructure failure it is necessary to determine how the economy responds and recovers from a disaster over time. Many researchers have investigated various forms of dynamic Leontief I-O models (Sage 1977; Miller and Blair 2009). The dynamic inoperability input-output model (DIIM) was introduced to model the process of recovery after a period of inoperability due to a disaster. The basic equation describing this system achieves this by using a resiliency matrix to determine the rate of recovery for each sector in the model (Lian and Haimes 2006). In this form, resiliency is a direct function of the rate of recovery and is determined using an exponential function that relates the initial level of inoperability and the recovery rate required to return the economy to normal conditions (Haimes et al. 2005b). When final equilibrium is reached the DIIM has the same form as the static IIM. With the addition of a stochastic term, it is possible to model the randomness associated with dynamic recovery. Sectors with high uncertainty will therefore follow an unstable path of recovery that ultimately affects all other sectors of the economy. Modelling the dynamic process of recovery enables dynamic interdependency to be explicitly modelled and the resilience of different economic sectors to be captured through an exponential recovery function.

The basic form of the dynamic input-output model is represented by Equation (4). It takes the same basic form as the classic Leontief model where the matrix $\mathbf{K}$ is a square matrix of capital coefficients and represents the willingness of the economy to invest in capital resources. The standard IIM approach can be extended to a 
dynamic I-O model using Equation (5). In this equation Matrix $\mathbf{K}^{*}$ represents the industry resilience coefficient matrix where each element, $k_{i}$ represents the resilience of sector $\boldsymbol{i}$ given an imbalance between supply and demand (Haimes et al. 2005a).

$$
\begin{aligned}
& \mathbf{x}(t)=\mathbf{A x}(t)+\mathbf{c}(t)+\mathbf{K} \dot{\mathbf{x}} \\
& \dot{\mathbf{q}}(t)=\mathbf{K}^{*}\left(\mathbf{A}^{*} \mathbf{q}(t)+\mathbf{c}^{*}(t)-\mathbf{q}(t)\right)
\end{aligned}
$$

\section{Results and Discussion}

\section{How to improve economic loss estimation from infrastructure failure Improving terminology and definitions}

There is a great deal of disagreement among disaster researchers as to what counts as an indirect cost (Rose 2004; Simpson et al. 2005; Okuyama 2007) definitions usually include loss in income due to reduced final demand for products, loss in revenues from damaged businesses, loss in intermediate demand due to disruptions in the supply chain (forward and backward) and loss in productive capacity. For example, Cochrane (2004) uses the simple definition that direct losses are the damages to property plus lost income as a direct result of the disaster, while the indirect cost is everything else. On the other hand, Hallegatte (2008) describes direct losses as the direct damage caused to physical infrastructure only (i.e., loss in stock capital value) while all flow losses occurring after the disaster are considered as indirect losses. Other authors such as Rose (2004) suggest using the term 'higher order effects' to describe flow losses to prevent confusion with terminology used by input-output literature elsewhere. If accurate comparisons of the economic losses are to be made, then accurate terminology needs to be agreed upon and consistently applied across different models. At present there is even confusion amongst researchers whether physical damage to infrastructure (a stock) should be described as an economic loss. A clear distinction needs to be made between damage to physical stock, losses in revenue, direct losses in economic output and indirect losses occurring elsewhere in the economy. There is also confusion in models that report 'higher economic growth' after a disaster but fail to account for the absolute loss in GDP. Even though economic growth might be higher after a disaster, the total output of the economy is still well below the ex-ante output had the disaster not occurred, thus only reporting economic growth might misrepresent the full effects of the disaster.

\section{Better modeling of physical and economic linkages}

The overall economic impact of a disaster is a combination of the size of the initial impact and the rate of recovery of the economy. Understanding economic loss therefore requires assessing the damage to capital infrastructure but also the losses associated with decreased economic output over the period of the recovery. Estimating economic losses from infrastructure failure requires implementing bespoke models that are able to incorporate the unique and idiosyncratic nature of infrastructure and their relationship within the economy. The relationship between infrastructure and the economy is not unidirectional. To date, the vast majority of hazard related research attempting to estimate indirect impacts make the assumption that linkages between infrastructure and other sectors of the economy can be represented purely by the financial flows between different sectors of the economy. Making this assumption is convenient as it allows inter-linkages to be represented and modeled using publicly available input output tables (Cochrane 1997; Rose 2004; Hallegatte 2008; Okuyama 2009), but unfortunately this leads to erroneous conclusions. Although it is true that a proportion of total economic disruption occurring within an economy is caused by a reduction in business activity from within the affected area, it is not true that all indirect effects within the rest of the economy are propagated through financial transactions alone.

For example, during the monsoon season in Thailand, major flooding caused many of the world's largest hard drive manufacturers to reduce output. At that time, hard drive maker Western Digital managed to produce only $60 \%$ of the 54 million hard drives it normally ships. The knock on effects of this disruption led to a decrease in sales to computer manufacturers and end consumers outside the initial area impacted by the hazard. In this example it is justifiable to use the standard economic input-output model to estimate the indirect economic effects on the economy due to a reduction in production capacity. However, disruption to physical infrastructure is very different to disrupting productive output. Infrastructure networks connect economic sectors through physical networks. When a physical infrastructure network fails, not only is there an economic consequence but there is also a physical consequence that must also be included in the analysis. Electricity networks may fail shutting down industrial activity, transportation systems may fail preventing the delivery of goods to market and telecommunication systems may fail preventing the communication of business activity and knowledge throughout the economy.

Several authors have tried to combine engineering based methods with economic models for transport infrastructure (Gordon et al. 1998; Cho et al. 2001; Kim et al. 2002) and for lifeline network models (Rose 2004). Romanoff and Levine (1986; 1989) developed the Sequential Interindustry Model (SIM) which introduced time-phased production, capacity and inventory to the 
standard Leontief model. Although originally developed to look at transient changes to economic activity, Okuyama (2004b) showed its potential value as a tool for estimating the economic impacts of disasters by taking into consideration the role of inventory within an economy. Still, to the authors knowledge there has been no attempt to incorporate both engineering and economic linkages across all infrastructure types in an economy. The assumption that all indirect economic effects can be modelled through financial transactions within the standard I-O table is erroneous, and will lead to incorrect loss estimation. This is because it does not account for the physical interdependencies across different sectors of the economy. The total economic effect will be a combination of physical and economic effects at the primary, secondary and tertiary levels (where tertiary effects are defined as the impacts on the economy caused by physical cascade effects outside the affected area).

Figure 1 is a graphical representation of primary, secondary and tertiary effects on the economy.

\section{Improving estimates of changes to economic structure}

The structure of the economy and the relationship between different economic sectors at a particular moment in time plays a significant role in determining macroeconomic vulnerability (Benson and Clay 2004). Economic structure is reflected in the relative importance of various sectors, in the patterns of ownership and systems of production, by the inter-sectoral linkages and the importance of productive capital in the economy. The role of critical infrastructure is therefore integral to understanding and estimating the true impacts of a disaster on an economy. This requires a deep understanding of the underlying relationships and flows of goods and services within the economy that rely on infrastructure services. One shortcoming of existing disaster related I-O research is the assumption of fixed technical coefficients. In a demand-pull quantity model, technical coefficients represent the quantity of inputs required for delivering each unit of final demand. In a supply-push price model, allocation coefficients represent the value of outputs that feed into other sectors in the economy.

Both the demand-pull and supply-push models assume the structure of the economy remains unchanged after a disaster. This assumption most likely does not apply, particularly after a large disaster has occurred. When resources are scarce prices adjust and substitution between similar goods occurs. If these substitutions are persistent then new industries will be developed and the structure of the economy may change. For example, a disaster may destroy a steel mill used to supply steel products to the construction industry. Timber, which is also a key sector of the economy, can sometimes be used as a substitute for steel. Thus supply and demand equilibrium positions shift as prices change. In another example, a surplus in one industry can generate revenues through increased exports, while this increase in revenue can be used to pay for imports that now experience higher demand. Under existing disaster I-O assumptions, it is assumed the economy retains the same structure during and after the disaster has occurred. Further research is required to understand how the underlying structure of an economy may change once the effects of the disaster have occurred.

\section{Incorporating uncertainty analysis into economic loss estimates}

The economic impact of infrastructure failure is highly uncertain. The scale of damage and level of economic disruption caused by infrastructure failure is a direct function of the hazard event, the vulnerability of infrastructure systems and the resiliency of the economy. Despite the probabilistic nature of natural hazards and the stochastic nature of economic consequences, deterministic models are still widely used to estimate economic losses resulting from disasters. Similar to the

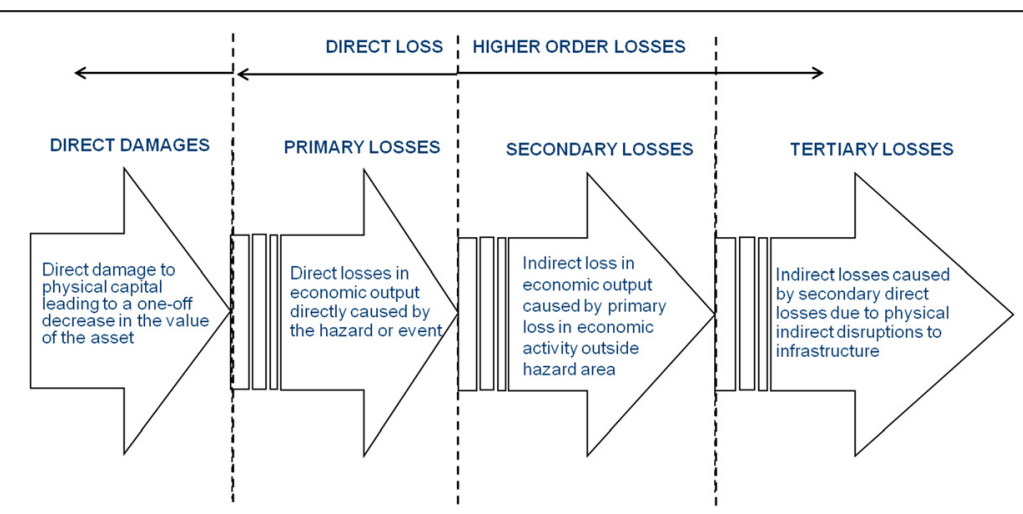

Fig. 1 Primary, secondary and tertiary losses 
transition which occurred in the field of flood risk management forty years ago (Hall 2014) 'economic risk management' still needs to undergo a transformation from managing risk deterministically, to modelling economic risk stochastically and therefore incorporating uncertainty.

The severity of economic loss is the end consequence that results from a combination of different conditions. The starting point for assigning uncertainty to economic loss estimates is to get better estimates of the upper and lower confidence bounds on the distribution of extreme events and their likely impacts. An analysis on the vulnerability of physical infrastructure systems will then provide some evidence on the likely impacts that may occur from an extreme event. Uncertainty analysis at this stage must also allow for non-linear discrete events, where a sudden change in conditions may result in sudden catastrophic failure. An example of this type of failure is the failure of a dike. Everything is fine and no damage occurs until the point when the dike fails. The final step to incorporating uncertainty into economic loss estimates is to understand the uncertainty of the recovery process. This will involve a good understanding of 'hard' factors such as access to physical capital, working and reliable infrastructure systems and an ability to raise finance. It will also involve understanding soft factors such as social support systems, political will and social cohesion. The more uncertainty there is surrounding these factors, the more imprecise and the larger will be the confidence bounds around final economic loss estimates. Once uncertainty and risk are appropriately accounted for informed choices can be made about reducing risk and assessing different mitigation or adaptation strategies.

\section{Conclusion}

This paper has proposed four distinct approaches for improving economic loss estimates resulting from infrastructure failure. Firstly, it is necessary to review and consolidate the various conflicting definitions used to describe economic loss. Secondly, it is important to distinguish between damage to capital assets on the one hand and losses to potential output on the other. Damage to capital is a decrease in the value of the physical capital stock, and the later is a reduction in the level of economic output and the relationship between them may be nonlinear. New infrastructure based I-O models must therefore incorporate physical interdependencies between different infrastructure systems as well as the economic interdependencies. Moreover, because physical linkages and economic linkages are two distinct but related forms of interdependency, models that conflate these two transmission processes will not accurately estimate the full impacts of infrastructure failure. Models that only attempt to measure physical interdependencies do not capture economic effects and models that rely on economic interdependencies to describe physical processes will not accurately capture the full effects of physical interdependency between sectors. Thirdly, a core assumption of I-O models is that the structure of the economy is retained during a disaster and during the recovery process. There is strong evidence to suggest that as supply and demand curves shift due to shortages in different sectors of the economy, equilibrium positions will shift, prices will change and substitution between products will result in changes to economic structure. Finally, an estimate of economic loss is the end product of a complex combination of interlinking effects beginning with the initial hazard; the vulnerability of physical infrastructure; and the resilience and recoverability of the economy. New research must start to make progress in quantifying the underlying uncertainty associated with final economic loss estimates as has been done in other fields of disaster related research.

This paper has shown that complex infrastructure systems are unique in their interaction and contribution to economic activity. Many different methods have been proposed to estimate the economic loss from infrastructure failure along with their strengths and weaknesses. But all methods fall-short of providing a panacea. The next generation of economic-infrastructure failure models will therefore need to overcome the limitations embedded within the existing methods and processes. It is hoped the next generation of models will overcome many of the limitations discussed in this paper and incorporate some of the suggested improvements.

\section{Abbreviations}

BAU: Business as usual; CBA: Cost benefit analysis; CGE: Computable general equilibrium model; DIIM: Dynamic input output modelling; GDP: Gross domestic product; I-O: Input-output; IIM: Inoperability input-output model.

\section{Competing interests}

The author declares that he has no competing interests.

\section{Author's contributions}

The author contributed all material to this paper except where explicitly stated.

\section{Acknowledgements}

This research was made possible through the Infrastructure Transition Research Consortium (ITRC) financially supported by the Engineering and Physical Science Research Council under grant EP/101344X/1.

The author would like to thank Professor Pete Tyler and the Department of Land Economy for managing the project at the University of Cambridge. Gratitude for initial feedback on early drafts is given to Professor Doug Crawford-Brown. Special thanks are given to Dr Raghav Pant and Dr Scott Thacker and other partners within the ITRC for their input on this project. Thanks also to Miriam Mendes for organizing the conference that made this special issue possible.

Received: 22 August 2014 Accepted: 2 September 2015

Published online: 16 September 2015 


\section{References}

Albala-Bertrand JM (2013) Disasters and the Networked Economy. Routledge, Milton Park, Abingdon, Oxon; New York, NY

Anderson CW, Santos JR, Haimes YY (2007) A Risk-based Input-output Methodology for Measuring the Effects of the August 2003 Northeast Blackout. Econ Syst Res 19:183-204. doi:10.1080/09535310701330233

Benson C, Clay E (2004) Understanding the Economic and Financial Impacts of Natural Disasters. World Bank Publications, Washington.

Brown T, Beyeler W, Barton D (2004) Assessing infrastructure interdependencies: The challenge of risk analysis for complex adaptive systems. Int J Crit Infrastruct 1:108-117

Buckle P (2005) Mandated definitions, local knowledge and complexity. What Disaster New Answ. Old Quest. Xlibris, Corp, Philadelphia, p 179

Cavallo E, Noy I (2010) The economics of natural disasters. [http://www.iadb.org/ res/publications/pubfiles/pubidb-wp-124.pdf]

Cavallo E, Galiani S, Noy I, Pantano J (2013) Catastrophic natural disasters and economic growth. Rev Econ Stat 95:1549-1561. doi:10.1162/REST_a_00413

Cho S, Gordon P, Moore JE II, Harry W.R, Masanobu S, and Stephanie C et al (2001) Integrating Transportation Network and Regional Economic Models to Estimate the Costs of a Large Urban Earthquake. J Reg Sci 41:39-65. doi:10.1111/0022-4146.00206

Cisen I, Clark W (1962) The methodological challenge of disaster research. Man Soc. Disaster 51:23

Cochrane H (1997) Economic impacts of a midwestern earthquake. "The Quarterly Publication of NCEER" Volume 11, Number 1, January 1997.

Cochrane H (2004) Economic loss: myth and measurement. Disaster Prev Manag 13:290-296

Cochrane HC, Eugene Haas J, Bowden M, Kates R (1974) Social science perspectives on the coming San Francisco earthquake: economic impact, prediction, and reconstruction. Institute of Behavioral Science, University of Colorado, Boulder, Colorado

Dacy DC, Kunreuther H (1969) The economics of natural disasters: implications for Federal policy. Free Press, New York.

De Mesnard L (2007) About the Ghosh model: clarifications. Univ. Burgundy CNRS Univ. III. Urbana-Champaign-Regional Econ. Appl. Labratory REAL LEG Econ. Ser. Work. Pap. No 6:

De Mesnard L (2009) Is the Ghosh model interesting? J Reg Sci 49:361-372

Deman S (1988) Stability of supply coefficients and consistency of supply-driven and demand-driven input - output models. Environ Plan A 20:811-816. doi:10.1068/a200811

Dietzenbacher E (1997) In vindication of the Ghosh model: a reinterpretation as a price model. J Reg Sci 37:629-651

Dietzenbacher E, Hoen A (2006) Coefficient stability and predictability in inputoutput models: A comparative analysis for the Netherlands. Constr Manag Econ 24:671-680

Ellson RW, Milliman JW, Roberts RB (1984) Measuring the Regional Economic Effects of Earthquakes and Earthquake Predictions*. J Reg Sci 24:559-579. doi:10.1111/j.1467-9787.1984.tb01048.x

Fritz CE, Marks ES (1954) The NORC Studies of Human Behavior in Disaster. J Soc Issues 10:26-41. doi:10.1111/j.1540-4560.1954.tb01996.x

Ghosh A (1958) Input-output approach in an allocation system. Economica 25:58-64. doi:10.2307/2550694

Gordon P, Richardson HW, Davis B (1998) Transport-related impacts of the Northridge earthquake. National Emergency Training Center, University of Southern California.

Guerra A-I, Sancho F (2011) Revisiting the original Ghosh model: can it be made more plausible? Econ Syst Res 23:319-328

Guimaraes P, Hefner FL, Woodward DP (1993) Wealth and income effects of natural disasters: an econometric analysis of hurricane Hugo. Rev Reg Stud 23:97-114

Haimes $Y Y$, Jiang $P$ (2001) Leontief-based model of risk in complex interconnected infrastructures. J Infrastruct Syst 7:1-12. doi:10.1061/(ASCE)1076-0342(2001)7:1(1)

Haimes YY, Horowitz BM, Lambert JH et al (2005a) Inoperability input-output model for interdependent infrastructure sectors. II: Case studies. J Infrastruct Syst 11:80-92. doi:10.1061/(ASCE)1076-0342(2005)11:2(80)

Haimes YY, Horowitz BM, Lambert JH, Santos JR, Lian C, and Crowther KG, et al. (2005b) Inoperability input-output model for interdependent infrastructure sectors. I: Theory and methodology. J Infrastruct Syst 11:67-79. doi:10.1061/ (ASCE) 1076-0342(2005)11:2(67)

Hall JW (2014) Applied Uncertainty Analysis for Flood Risk Management.
Hallegatte S (2008) An adaptive regional input output model and its application to the assessment of the economic cost of Katrina. Risk Anal 28:779-799. doi:10.1111/j.1539-6924.2008.01046.x

Hallegatte S (2013) Modeling the Role of Inventories and Heterogeneity in the Assessment of the Economic Costs of Natural Disasters. Risk Anal n/a-n/a. doi:10.1111/risa.12090

Hallegatte S, Przyluski V (2010) The economics of natural disasters: concepts and methods. World Bank Policy Res. Work. Pap. Ser. Vol

Kim TJ, Ham H, Boyce DE (2002) Economic impacts of transportation network changes: Implementation of a combined transportation network and input-output model*. Pap Reg Sci 81:223-246. doi:10.1111/j.14355597.2002.tb01231.x

Kotzanikolaou P, Theoharidou M, Gritzalis D (2013) Assessing n-order dependencies between critical infrastructures. Int J Crit Infrastruct 9:93-110 doi:10.1504/IJCIS.2013.051606

Levine SH, Romanoff E (1989) Economic impact dynamics of complex engineering project scheduling. IEEE Trans Syst Man Cybern 19:232-240. doi:10.1109/21.31029

Lian C, Haimes YY (2006) Managing the risk of terrorism to interdependent infrastructure systems through the Dynamic Inoperability Input-output Model. Syst Eng 9:241-258. doi:10.1002/sys.20051

MacKenzie CA, Santos JR, Barker K (2012) Measuring changes in international production from a disruption: Case study of the Japanese earthquake and tsunami. Int J Prod Econ 138:293-302. doi:10.1016/j.jpe.2012.03.032

Mileti D (1999) The Changing Risk Landscape: Implications for Insurance Risk Management. Edited by Neil R. Britton. Proceedings of a Conference sponsored by Aon Group Australia Limited

Miller RE, Blair PD (2009) Input-output Analysis Foundations and Extensions. Cambridge University Press, Leiden

Okuyama, Chang (2004) Modeling spatial and economic impacts of disasters. Springer, Berlin

Okuyama Y (2004b) Modeling spatial economic impacts of an earthquake: inputoutput approaches. Disaster Prev Manag 13:297-306

Okuyama Y (2007) Economic modeling for disaster impact analysis: past, present, and future. Econ Syst Res 19:115-124. doi:10.1080/09535310701328435

Okuyama Y (2008) Critical review of Methodologies on disaster impacts estimation. Backgr. Pap. EDRR Rep Elsevier, USA

Okuyama Y (2009) Economic impacts of natural disasters development issues and emperical analysis.

Okuyama Y, Hewings GJD, Sonis M (2004) Measuring Economic Impacts of Disasters: Interregional Input-output Analysis Using Sequential Interindustry Model. In: Okuyama DY, Chang PSE (eds) Model. Spat. Econ. Impacts Disasters. Springer, Berlin Heidelberg, pp 77-101

Oosterhaven J (1988) On the plausibility of the supply-driven input-output model. J Reg Sci 28:203-217. doi:10.1111/j.1467-9787.1988.tb01208.x

Oosterhaven J (1989) The supply driven input-output model: a new interpretation but still implausible. J Reg Sci 29:459-465. doi:10.1111/j.1467-9787.1989.tb01391.x

Oosterhaven J (2012) Adding supply-driven consumption makes the Ghosh model even more implausible. Econ Syst Res 24:101-111

Perry RW, Lindell MK, Greene M (1981) Evacuation planning in emergency management. Lexington Books. Quarantelli 1998 https://books.google.co.uk/ books?id=YSkiAAAAMAAJ\&q=Evacuation+planning+in+emergency +management+citation\&dq=Evacuation+planning+in+emergency + management+citation\&hl=en\&sa $=X \& v e d=0 C C K Q 6 A E$ wAGoVChMIv573ra7|xwIVAirbChOMZAWD

Quarantelli EL (2005) What is a Disaster?: A Dozen Perspectives on the Question. Routledge. London; New York

Resurreccion JZ, Santos JR (2013) Uncertainty modeling of hurricane-based disruptions to interdependent economic and infrastructure systems. Nat Hazards 1-22. doi:10.1007/s1 1069-013-0760-5

Rinaldi SM, Peerenboom JP, Kelly TK (2001) Identifying, understanding, and analyzing critical infrastructure interdependencies. IEEE Control Syst 21:11-25. doi:10.1109/37.969131

Rodriguez H, Quarantelli EL, Dynes R (2007) Handbook of Disaster Research. Springer Science \& Business Media, USA

Romanoff E, Levine SH (1986) Capacity limitations, inventory, and time-phased production in the sequential interindustry model. Pap Reg Sci 59:73-91. doi:10.1111/j.1435-5597.1986.tb00983.x

Rose A (2004) Defining and measuring economic resilience to disasters. Disaster Prev Manag 13:307-314 
Rose A, Allison T (1989) On the plausibility of the supply-driven input-output model: emperical evidence on joint stability. J Reg Sci 29:451

Rose A, Wei D (2013) Estimating the economic consequences of a port shutdown: the special role of resilience. Econ Syst Res 25:212-232. doi:10.1080/09535314.2012.731379

Rose A, Benavides J, Chang SE, Szczesniak P, and Lim D (1997) The regional economic impact of an earthquake: direct and indirect effects of electricity lifeline disruptions. J Reg Sci 37:437-458. doi:10.1111/0022-4146.00063

Sage AP (1977) Methodology for large-scale systems. McGraw-Hill

Santos JR, Haimes YY (2002) Demand-Reduction Input-output (I-O) Analysis for Modeling Interconnectedness. Risk-Based Decis. Water Resour. X., pp 104-118

Santos JR, Haimes YY (2004) Modeling the demand reduction Input-output (I-O) inoperability due to terrorism of interconnected infrastructures. Risk Anal Int J 24:1437-1451. doi:10.1111/j.0272-4332.2004.00540.x

Simpson DM, Rockaway TD, Weigel TA, Coomes PA, and Holloman CO (2005) Framing a new approach to critical infrastructure modelling and extreme events. Int J Crit Infrastruct 1:125-143

Smith D (2005) Through a glass darkly. What Disaster New Answ. Old Quest

Stallings RA (1998) Disaster and theory of social order. What Disaster Perspect. Quest. Psychology Press, pp 127-145

Tsuchiya S, Tatano H, Okada N (2007) Economic loss assessment due to railroad and highway disruptions. Econ Syst Res 19:147-162. doi:10.1080/09535310701328567

Van der Veen A, Vetere Arellano AL, Nordvik JP (2003) In search of a common methodology for damage estimation. Jt. NEDIES Univ. Twente Workshop Rep. EUR 20997

Von Peter G, Von Dahlen S, Saxena SC (2012) Unmitigated Disasters?: New Evidence on the Macroeconomic Cost of Natural Catastrophes

Yu KDS, Tan RR, Aviso KB, Promentilla MAB, and Santos JR (2014) A vulnerability index for post-disaster key sector prioritization. Econ Syst Res 26:81-97. doi:10.1080/09535314.2013.872603

\section{Submit your manuscript to a SpringerOpen ${ }^{\circ}$} journal and benefit from:

- Convenient online submission

- Rigorous peer review

- Immediate publication on acceptance

Open access: articles freely available online

- High visibility within the field

- Retaining the copyright to your article

Submit your next manuscript at $>$ springeropen.com 